Article

\title{
Sustainable Idea Development Mechanism in University Technology Commercialization (UTC): Perspectives from Dynamic Capabilities Framework
}

\author{
Insu Cho ${ }^{1}$, Young Hoon Kwak ${ }^{2}$ and Jaehyeon Jun ${ }^{3, *}$ \\ 1 Department of Industrial and Management Engineering, Sun Moon University, Asan-si 31460, Korea; \\ incho@sunmoon.ac.kr \\ 2 Department of Decision Sciences, The George Washington University, Washington, DC 20052, USA; \\ kwak@gwu.edu \\ 3 Department of Industrial Engineering, Yonsei University, Seoul 03722, Korea \\ * Correspondence: theojay@yonsei.ac.kr; Tel.: +82-2-2123-7776
}

Received: 16 October 2019; Accepted: 31 October 2019; Published: 4 November 2019

check for updates

\begin{abstract}
Universities pays a lot of attention and investment in the technology commercialization for its sustainable development and social contribution under Korean government-driven policies. However, when compared to US or European universities, the outcomes of the technology commercialization in universities are relatively inactive. Therefore, this study aims to propose a new idea-oriented framework of University-Technology Commercialization (UTC). To achieve this, this study explores the sustainable mechanism from idea to technology commercialization in the volatile environment by employing dynamic capabilities framework. This study employed structural equation modeling (SEM) to identify causal relationships among the variables with a 2014 to 2016 dataset from 'Higher Education in KOREA'. This study collected national and cross-sectional data from different time periods to design our longitudinal study. Our study examines UTC activities related to sustainable idea development mechanism from dynamic capability framework. The results show the importance of start-up clubs as a first step for idea exploration in university technology commercialization and patents as important for both technology transfers and start-ups. Our findings offer new UTC directions for university policy makers.
\end{abstract}

Keywords: university technology commercialization; sustainable idea development mechanism; technology transfers; start-ups; dynamic capabilities; longitudinal research

\section{Introduction}

\subsection{Research Background}

The university is considered not only as a provider of education and research, but also a technology commercialization center for scientific ideas or knowledge [1]. Many research-oriented universities have actually become more proactive in their efforts to commercialize innovative knowledge and technologies [2]. Technology commercialization refers to a university's various commercial usages of intellectual property (IP), such as patents, copyrights and research publications, including selling or licensing IP to firms for commercialization, and internal use of IP [1,3].

Carayannis and Dubina [1] proposed two basic technology commercialization models: (1) a license agreement with an existing firm that is interested in new research and technology, and (2) start-ups using the university's IP. Typically, a university commercializes a technology through the licensing of an IP to a large firm, which eventually develops the IP into a commercial good [3,4]. A university profits from an up-front agreement for the license or royalty payments as a percentage of technology 
sales from the contracted firms. Many universities are interested in the start-ups by university faculty, researchers and students with their IP as technology commercialization [4]. In this study, start-ups are defined as the concept of commercial idea spinoff to create social and economic value by clarifying and commercializing the idea developed by university member (professors, researchers and students) $[5,6]$. For example, some universities including Massachusetts Institute of Technology (MIT) routinely commercialize their technology through start-ups [7]. This trend demonstrates the university's effort toward alternative commercialization to enhance sustainable revenue in the IP market [8].

For the aforementioned two types of technology commercialization models, researchers have increasingly attempted to provide valuable implications by analyzing the phenomenon based on success cases. However, empirical research is still lacking to discover a technology commercialization mechanism. Previous research related to university technology commercialization (UTC) revealed that an innovative idea involves key resources and initial points from the UTC models [9]. A university should be able to sense an innovative idea and help it to be commercialized by university members [10].

\subsection{Research Purpose and Questions}

In South Korea, many universities have provided various programs to induce and assist start-ups due to interests in start-ups by students or young researchers under government-driven policies. Therefore, we aim to explore the sustainable mechanism from idea to technology commercialization in the volatile environment by employing dynamic capabilities framework [11].

To achieve the research purpose, we suggest three research questions (RQ):

RQ1. How are ideas created in a university? We explore which environmental or cultural features of a university are needed to create the commercial idea, which is the key resource of UTC.

RQ2. What process is needed to transform these ideas to business values for licensing and start-ups? Considering that the commercialization of a university's technological inventions is more complex and vibrant, the dynamic capabilities framework is suitable to provide a theoretical background.

RQ3. What is the causal relationship between the main activities of the universities in the UTC process? This study empirically examines the causal relationships among specific university activities and outcomes of UTC, such as technology transfers and start-ups, with a longitudinal dataset. This study employs structural equation modeling (SEM) to identify and explain these causal relationships.

Our findings will provide implications for a special themed section of university activities, related to the sustainable commercialization of research and technology. Our conceptual model also provides an understanding of an idea's commercialization process by adopting a dynamic capability framework; sensing and seizing to transforming an idea. Our research findings contribute how universities might better manage their capabilities to commercialize ideas.

The remainder of this study is organized as follows: Section 2 presents the conceptual background, reviews the dynamic capabilities theory and describes how to apply this theory in a UTC context, with the conceptual model as a UTC mechanism. Section 3 describes our dataset and variables for longitudinal research, and Section 4 conducts a path analysis to identify relationships among the variables using structural equation modeling with the partial least squares (PLS) program. Section 5 discusses our key findings, and provides both theoretical and practical implications for future research in this area.

\section{Conceptual Background}

\subsection{Dynamic Capabilities}

Dynamic capabilities are widely considered to incorporate strategies, structures and environments that enable organizations to sustain superior performance in a changing environment [12]. Dynamic capabilities refer to a firm's capability to suitably match its resources with the market environment to impact competitive advantage and organizational performance [13-15]. Dynamic capabilities contrast with operational capabilities by focusing on the abilities to integrate, build and reconfigure internal 
and external resources to address rapidly changing environments $[13,14]$. Resources in dynamic capabilities can be understood as 'anything that could be thought of as a strength or weakness in a given organization' [16].

Teece [11] divided dynamic capabilities into three capacities to describe how dynamic capabilities configure resource bases: (1) sense opportunities; (2) seize opportunities and (3) redeploy and reconfigure, or create, extend and modify their resource base. Previous literature has considered dynamic capabilities as factors, processes or frameworks that influence a firm's competitive advantage relative to changing environments [17].

According to the dynamic capabilities framework [11], firms sense and seize valuable growth opportunities, then transform their organizations in the pursuit of these opportunities. The cognitive underpinnings of dynamic managerial capabilities for sensing and seizing have recently received growing interest, including at such a level as to match opportunities to organizational capabilities [18].

Dynamic capabilities positively influence organizations in multiple ways. Specifically, dynamic capabilities transform the firm's existing resources in such a way that a new bundle or configuration of resources is created; thus, the firm can sustain or enhance its competitive advantage [19].

Thus, dynamic capabilities act as mediating factors between a firm's resources and competitive advantage to determine the product positioning in the market. Dynamic capabilities also help firms systematically address the issues by sensing opportunities and threats, making timely decisions and implementing strategic decisions [17]. Additionally, dynamic capabilities adjust their operations to decrease costs [20].

Prior researches regarding dynamic capability have attempted to adopt various contexts and verify its empirical impacts on the real business context. Several researches try to build a more robust concept of dynamic capability. Tsai [21] suggested the radical innovation commercialization model that has an impact on the dynamic marketing capabilities of radical innovation commercialization in international technology-intensive firms. The model provided four types of capability (market knowledge management capability, customer value co-creation capability, collaborative networking capability and corporate branding capability) for commercialization performance of radical innovation.

Bruni and Verona [22] adopted the concept of dynamic marketing capabilities to product development process of pharmaceutical firms. They verified how dynamic marketing capabilities support the creation of new products and the reconfiguration in the new product development process. They highlighted the importance of managing market knowledge in the initial phases of the development process and provided implications for how firms manage their market knowledge and systems regarding human resources and social capital. Pandza and Thorpe [23] presented another perspective by discussing the managerial agency's role in creating and shaping dynamic capabilities. They attempted to integrate the role of managerial agency into the concept of dynamic capabilities and identified two cognitive processes: creative search and strategic sense-making, as missing dimensions in the dynamic capability concept. Pandza and Thorpe [23] suggested that these cognitive processes enable a better understanding of the dynamics of capability development. O'Connor, Paulson [24] identified the power of network comprised of rich, powerful, reaching, extendable intelligent and authority features to develop radical innovation dynamic capabilities by analyzing twelve US large firms.

Recently, many universities have focused on technology commercialization with innovative ideas beyond only patent application and research publication. Based on prior studies on the utilization of dynamic capabilities in a business context, this study attempts to apply dynamic capabilities into a university setting for technology commercialization. This study explores the sustainable commercialization mechanism of an idea in a university setting, based on a dynamic capabilities framework composed of sensing, seizing and transforming capabilities.

\subsection{Exploring Idea as Sensing}

Sensing capabilities, as a first step in dynamic capabilities, involve exploring opportunities and crises, both within and outside organizations. Sensing capabilities relate to scanning, creating, learning 
and interpreting activities to explore business issues internally and externally [11]. As a firm's sensing relates to changing business environments [25], its activities include market-searching efforts to identify new opportunities [26]. These efforts require the organization to maintain close relationships with customers, suppliers and R\&D partners, and to observe the industry's best practices [12]. Generally, new issues and ideas are recognized by market needs and technology opportunities [11]. Organizations then begin to plan a new business model and design new products or services based on this new issue or idea. Therefore, it is necessary to find various knowledge and technology sources for sustainable innovation [27]

Regarding universities, the initial idea for technology commercialization originates with industry needs or scientific discovery. Sensing initial idea and supporting sensing activities are an important capability in UTC. Thus, the university has operated and supported various programs for professor and student participation to intensify sensing activities [28]. The representative sensing programs to explore the idea include the start-up club and start-up class. A start-up club is a student-centered organization to conduct start-up-related activities. When a recruiting announcement for a start-up club is made at a university, interested students submit a start-up plan with main business items. Then the university evaluates the plans and selects the clubs. Selected start-up clubs will be assigned a professor as a mentor and receive spatial and monetary supports from the university. Start-up clubs present their results at contests or conferences and receive the verification or the investment to give shape to idea. The university regularly evaluates whether students in start-up are progressing well with their plan and supports deficiencies [29].

Rampersad [30] mentioned that students do play a critical role of UTC. Students in the club from various knowledge domains scan theoretical and practical areas to extract creative and meaningful ideas. As this club is relatively free and unrestricted, a high probability exists to discover novel ideas. The other program is a start-up class. Similar to entrepreneurial education, a start-up class provides various knowledge and methodologies related to start-ups and technology development [31].

As for the differences between the two classes, the entrepreneurial education focuses on general entrepreneurial activities and mindset including idea creation, R\&D and IP strategies, and how to commercialize them [32].

On the other hand, the start-up classes focus more on exploring and developing commercial idea in a topic related to their specific major. In other words, start-up classes focus on educating start-up methodologies and theories with term project based on their specific major, and are operated by each individual department. For example, AI based start-up class in the department of computer science educates AI technology and explore new idea to develop the specific products or services. In this case, the commercializing idea is more specific and professional.

According to a survey from the Karl Eller Centre-Berger Entrepreneurship Program at University of Arizona [33], this class increases the possibility of start-ups from university members. Thus, these programs could be considered as activities to explore new ideas. Similarly, business-oriented organizations have sensing activities in these programs, including three processes: 1) scanning, 2) evaluation and 3) detailing [34]. The scanning process refers to students' or faculties' extensive discovery of new and useful issues, to be solved with the theoretical opportunity recognition perspective [35]. The evaluation process involves quickly screening a particular opportunity or need to extract a creative idea with development feasibility [36]. The detailing process includes precisely defining and elaborating the idea.

\subsection{Specifying Idea as Seizing}

The second step in dynamic capabilities is the process to seize opportunities by formulating a strategic response [37]. This process involves developing specific resources from an idea [38]. Various ideas explored and discovered in the sensing phase must be specifically translated into valuable propositions [39]. Timely decision-making is important in this step to quickly formulate, evaluate and choose strategic orientations to adapt to changing environments [40]. Therefore, seizing activities can be divided into 'idea evaluation and selection' and 'idea detailing' [12,34]. Idea evaluation and 
selection considers which idea is most likely to be accepted in the market [11]. Diehl and Stroebe [41] suggested that diverse perspectives are necessary to evaluate and choose ideas. Simultaneously, an organization must establish specific procedures to evaluate options and select the most adequate idea for its purpose. Idea detailing refers to specifying an idea to use as a valuable resource.

In the university context, seizing capabilities translate a rough, tacit idea to a specific, robust idea as a type of intellectual property (IP) in technology commercialization. Different IP, such as patents and research publications, are assigned to university members, including faculties, researchers, and students, to provide incentives to engage in $R \& D$ activities. Therefore, many universities have recently become interested in commercially oriented research to address the industry's needs [42]. University members select the idea with a high possibility of success and business value among various options through discussion. Patents and publication as specific idea as well as internal discussion are evaluated by experts with various perspectives in a patent application and registration, and paper review process, as suggested by Diehl and Stroebe [41]. In this process, the idea is verified to have academic and practical values that can be documented.

They then specify the idea as a patent or research publication to utilize and protect it, depending on the idea's characteristics [43].

Many previous research studies identified a deep relationship between patent and technology commercialization, such as licensing or selling patent, and start-ups with patent [4]. However, evidence is still lacking as to the relationship between research publications and technology commercialization.

\subsection{Commercializing Idea as Transforming}

The final step in the dynamic capabilities framework involves transforming or reconfiguring capabilities, or maintaining organizational competitiveness through enhancing, combining, protecting and reconfiguring existing resources [11]. Teece [11] highlighted resources 'orchestration' processes to combine the various parts and continuously maintain competitive advantage. A key strategy in transforming includes discovering new resource combinations, both inside the organization and in external supporting institutions. These capabilities should consider the organizational design to achieve its strategic goals [37].

Organizations need flexibility in this step to decompose, recombine and internalize resources and capabilities to respond to internal and external changes [34,44]. They manage, match and align existing operational capabilities to exploit new opportunities; these capabilities play key roles, in that the new business process is applied into an organization, or new products or services are released into the market [22].

Universities have recently implemented various programs to transform a specific idea into technology commercialization. Recent university technology commercialization patterns operate with institutions (e.g., technology transfer offices), the agents involved in technology commercialization, academic spin-offs and university-industry cooperative research centers $[45,46]$. According to the previous study, the University of Technology Transfer Offices (TTOs) are considered important because they have a wide range of abilities to facilitate the commercial exploitation of research results [47]. Makkonen and Inkinen [48] also stress role of agents to form formal and informal network to interactions. This study reviews these patterns to focus on two technologies commercialization types: (1) technology transfer to an existing company, which is interested in a new intellectual property (IP); and (2) start-ups using the university's IP.

Technology transfer activities are divided into selling IP to other companies, and license agreements with other companies. As universities must convince various stakeholders, their technology transfers are rather complex [49]. Therefore, specialized university institutes, such as technology transfer offices (TTOs), is a key facilitator to manage technology commercialization by professionally handling stakeholders [50].

Previous research notes that start-ups are spin-offs that depend on licensing or the assignment of a university's IP for initiation [49], and faculties or star researchers primarily establish them. As it is 
important to have many of these institutions generating outstanding research [42], incentives for the faculty that operate them are considered an important success factor in start-ups [51]. Recently, many students and young researchers have participated in start-ups, and strong network ties among TTOs, venture capitalists, business angels, IP specialists (e.g., law firms) and entrepreneurs have become increasingly important in this context [52,53]. This indicates that recent technology transfers must consider not only the technology's internal capacity, but also its external environmental requirements [54].

\subsection{Conceptual Model}

We suggest a research model customized in sustainable university technology commercialization (UTC) and based on a dynamic capabilities framework (Figure 1). The sensing step extracted two types of university programs to explore an idea. Start-up clubs and classes are university programs that provide opportunities to formally or informally explore innovative and novel ideas. As this idea is immature and includes raw resources, the next step involves specifying and elaborating the idea for its utilization and protection. The methods used in a university to clarify the idea involve converting IP to patents or research publications.

Therefore, given that many initial ideas require substantial resources to be specified as IP, it is likely that exploring activities to discover new ideas positively relates to IP development. This study uses two IP factors-patents and research publications- to represent the UTC's seizing capabilities. The university experiences a transformation stage, as this IP ultimately becomes technology commercialization; thus, this IP is an important resource for university technology commercialization. For example, Shane [55] found that universities' patents with greater domestic and international patent class coverage were highly predictive of a technology's development through the formation of a start-up firm. As aforementioned, technology commercialization methods include technology transfer and start-ups. Therefore, it is likely that specifying activities to develop IP positively relate to IP commercialization.

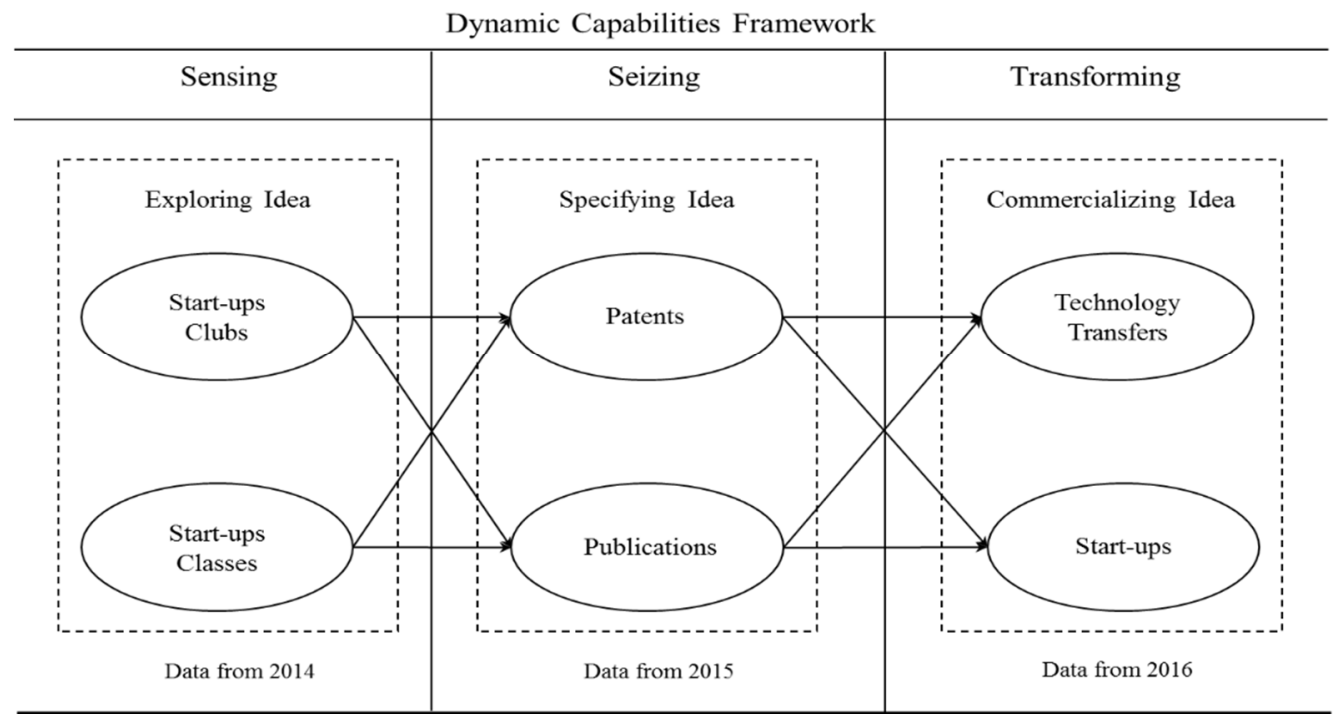

Figure 1. Conceptual causal relationship model based on a dynamic capabilities framework.

\section{Research Method}

\subsection{Dataset}

Our sample was collected from an annual survey from 'Higher Education in Korea' [56]. This survey provides the only comprehensive national source of data on technology commercialization-related information from all Korean universities. This education information service also provides only three 
years of data. Therefore, this study gathered and filtered 244 datasets for the period from 2014 to 2016, which are the most recent three years from 2017 when data was collected. Although the period of data provided is limited, these data sets have the advantage of tracking information related with start-up activities in each university on a yearly basis. Therefore, we first extracted and arranged the information from each university on a yearly basis.

This study employed a longitudinal method to identify causal relationships among the variables, as it is necessary to empirically verify whether each activity for UTC sequentially affects the next from a long-term perspective. We collected national and cross-sectional data from different time periods to design our longitudinal study. According to a previous study, which is on the effects of professional development on teachers' instruction, it also used national and cross-sectional data from different time periods to conduct their longitudinal study in the education context [57]. They designed their study by setting three time periods, the fall of 1997, the spring of 1998, and the spring of 1999, and collected survey data for a year from each period. The prior study, which is regarding to relationship between sources of capabilities and technology commercialization, also used a 3-year lag cross-sectional data to evaluate the long-term effect of independent variables on dependent variables [58]. Considering the methods of earlier studies, from 2013 to 2014, we gathered data regarding sensing capabilities to construct independent variables. From 2014 to 2015, we gathered data regarding seizing capabilities to construct mediating variables. Finally, from 2015 to 2016, we gathered data regarding transforming capabilities to construct dependent variables. All data used in the study were collected under the same conditions except time period.

\subsection{Variables}

\subsubsection{Transforming Variables}

Two transforming variables were included as dependent variables to explain this study's commercializing idea. We use start-ups and technology transfer from the 2016 survey data to represent university technology commercialization performance. Start-ups are the first dependent variables, as these establish business by applying ideas specified by such university members as professors and students. This study measures the number of start-ups and their revenue as factors that indicate university technology commercialization performance.

The second variable is technology transfer. Recently, universities have significantly concentrated their efforts to make profits based on their patent or research output. Two types of technology transfer contracts exist: technology sales and patent licensing. This study measures the number of technology transfer contracts and their total revenue.

\subsubsection{Seizing Variables}

Two variables were used to explain the shaping of a creative idea. The idea, captured by sensing capabilities, is specified as both patents and research publications by faculty, researchers and students.

Thus, patents and research publications are the result of a development process to transform intangible, abstract ideas into tangible resources. These variables (patents and research publications) are intermediate outcomes to mediate between the sensing and transforming capabilities, and were collected from the 2015 survey data. We measured the sum of domestic and international patents; research publications were also measured by the sum of domestic and international publications. Previous research cited the importance of the factor regarding patent as one of the important determinants of university technology transfer success. They adopted the variable of the patenting control ratio (PCR), which is calculated as value of number of patents issued out of total number of patent applied. We also agreed with the importance of patents in our study. Therefore, in this research, we constructed the patent as the sum of domestic and international patent application, using the data from 'Higher Education in KOREA' [59]. 
The data from 'Higher Education in KOREA' about domestic publications has separately investigated the Korea Citation Index (KCI) journals, which is certified and managed by the National Research Foundation (NRF) of Korea, and general academic journals that are not managed by NRF. It has also separately investigated international publications into two types of (1) science citation index (SCI) presented by Thomson Reuters and SCOPUS certified by ELSEVIER as professional journals and (2) other general academic journals. In this study, KCI, SCI and SCOPUS, which are deemed to be the least quality assurance, were selected and used as indicators to measure the capability to embody and document ideas.

\subsubsection{Sensing Variables}

We employed two independent variables as independent variables from the 2014 survey data to gather the sensing capabilities that explore creative ideas in universities. New idea exploration could be activated by start-up clubs and classes, or capstone design programs. Start-up club activities were measured by employing the number of students registered in start-up clubs at each university. Second, start-up classes were defined as formal education to provide start-up methodologies and theories with usually term project based on their specific major by each department at university. We measured the number of start-up-related major classes at each university. Table 1 illustrates the above variables and measurement items.

Table 1. Descriptions of the variables.

\begin{tabular}{|c|c|c|}
\hline Variables & Measurement Item & Survey Year \\
\hline Technology & $\begin{array}{l}\text { (TL1) Number of technology transfer contracts, such as technology sales or } \\
\text { patent licensing, during one year }\end{array}$ & 2016 \\
\hline \multirow{3}{*}{ Start-ups } & $\begin{array}{l}\text { (TL2) Amount of revenue actually deposited for technology transfer } \\
\text { contracts, such as technology sales or patent licensing, during one year }\end{array}$ & 2016 \\
\hline & $\begin{array}{l}\text { (STUP1) Number of enrolled start-ups by professors or students during } \\
\text { one year }\end{array}$ & 2016 \\
\hline & $\begin{array}{l}\text { (STUP2) Total sales amounts of enrolled start-ups by professors or students } \\
\text { during one year }\end{array}$ & 2016 \\
\hline \multirow{2}{*}{ Patents } & (PAT1) Number of domestic patent applications during one year & 2015 \\
\hline & (PAT2) Number of international patent applications during one year & 2015 \\
\hline Publications & $\begin{array}{l}\text { (PUB) Number of domestic and international publications above a certain } \\
\text { quality level during one year }\end{array}$ & 2015 \\
\hline \multirow[t]{2}{*}{ Start-up Clubs } & $\begin{array}{l}\text { (SC1) Number of student clubs that specialize in start-ups supported by } \\
\text { university }\end{array}$ & 2014 \\
\hline & (SC2) Number of students to be registered in start-up clubs & 2014 \\
\hline Start-up Classes & $\begin{array}{l}\text { (SCL) Number of start-up classes that educate start-up methodologies and } \\
\text { theories with term project based on their specific major }\end{array}$ & 2014 \\
\hline
\end{tabular}

\section{Result}

A data analysis was conducted using a structural equation modeling technique with partial least squares (PLS), using Smart PLS 2.0. A PLS regression technique generalizes and combines features from the principal component analysis and multiple regressions, and aims to predict or analyze a set of dependent variables from a set of independent variables or predictors [60]. Therefore, the PLS is primarily intended for causal-predictive analyses in highly complex situations. The PLS has several advantages for regression-based path analyses. First, PLS is not as restrictive on the sample as multivariate, normal data distributions [61], and was a suitable method considering that our dataset did not follow normal data distributions.

Second, as this method is implemented to construct predictive models when there are multiple, highly collinear factors [62], it is useful to address collinearity problems among the variables in multiple regressions $[63,64]$. We first conducted a descriptive statistical analysis and determined the measurement instrument's validity, then tested our hypotheses. 


\subsection{Descriptive Statistical Anlaysis}

First, descriptive statistics were calculated from 244 university samples in South Korea for each of the variables (means, standard deviations, minimum and maximum values, median and skewness), and are listed in Table 2.

Regarding Korean universities, the revenue from technology transfer was relatively higher than that from start-ups. Thus, universities still focused on technology sales or licensing to other firms instead of their own spin-offs. Further, considering that research publications were overwhelmingly larger in number than patents, the former was relatively faster and easier than the latter in Korea. This means that many university members expressed their ideas through publication.

Table 2. Descriptive statistics.

\begin{tabular}{ccccccccc}
\hline Variables & Indicators & $\mathbf{N}$ & Mean & Std. Dev. & Min. & Max. & Median & Skewness \\
\hline Technology & TL1 & 244 & 16.41 & 26.947 & 0 & 141 & 1 & 2.1 \\
Transfer & TL2 & 244 & $\$ 280,406$ & 650,311 & 0 & $\$ 4,126,652$ & 10000 & 3.49 \\
Start-ups & STUP1 & 244 & 3.62 & 5.262 & 0 & 26 & 1 & 2 \\
& STUP2 & 244 & $\$ 43,722$ & 202,993 & 0 & $\$ 2,794,050$ & 0 & 10.98 \\
Patents & PAT1 & 244 & 41.48 & 90.322 & 0 & 691 & 3.5 & 3.89 \\
Publications & PAT2 & 244 & 4.78 & 15.561 & 0 & 127 & 0 & 5.09 \\
Start-up Clubs & PUB & 244 & 302.42 & 420.078 & 0 & 3156 & 151.85 & 2.97 \\
Start-up Classes & SSC1 & 244 & 11.03 & 16.180 & 0 & 114 & 1 & 2.25 \\
\hline
\end{tabular}

\subsection{Convergent and Discriminant Validity}

We then analyzed the constructs for convergent and discriminant validity. Convergent validity can be assessed in PLS-based SEM using the following criteria: (1) the constructs' average variance extracted (AVE) should exceed 0.5, and (2) the composite reliability (CR) and Cronbach's alpha should exceed $0.7[65,66]$. Except for single measurement items, such as start-up classes and publications, other measurement items demonstrated good convergent validity, as Table 3 illustrates.

Table 3. Convergent validity.

\begin{tabular}{cccc}
\hline & AVE & Composite Reliability & Cronbach's Alpha \\
\hline Start-ups & 0.715 & 0.834 & 0.706 \\
Start-up Clubs & 0.903 & 0.949 & 0.894 \\
Technology Transfers & 0.887 & 0.940 & 0.873 \\
Patents & 0.911 & 0.953 & 0.903 \\
\hline Criteria: AVE $>$ 0.5, CR and Cronbach's $\alpha>0.7$ by Fornell and Larcker [65] and Gefen et al. [66].
\end{tabular}

Second, discriminant validity was estimated using Fornell and Larcker's guidance [65], in which the square root of each construct's AVE should exceed the correlation between it and any other constructs. Table 4 represents the correlation matrix, with the correlations among the constructs and the square root of AVE displayed diagonally. As the diagonal values exceeded the inter-construct correlations, the discriminant validity test results were acceptable.

\subsection{Path Analysis of the Conceptual Model}

We examined the path analysis of the conceptual model using PLS. Figure 2 represents the results of the PLS structural model assessment, including the overall explanatory power and estimated path coefficients. Moreover, we tested our research model's goodness-of-fit index (GoF). According to Henseler and Sarstedt [67], a model fit test can be conducted using the average communality, which refers to the average proportion of the variance explained when regressing the reflective indicators on their latent variables, and the average $\mathrm{R}^{2}$ of the endogenous latent variables from the Smart PLS report. 
These two average values were multiplied and the square root was determined, providing a GoF value of 0.598. According to evaluation standards of Tenenhaus, Vinzi [68], a GoF value that exceeds 0.36 is considered as high. Thus, the test results indicate that our research model had a high goodness-of-fit.

Table 4. Discriminant validity.

\begin{tabular}{ccccccc}
\hline & Start-ups & $\begin{array}{c}\text { Start-up } \\
\text { Classes }\end{array}$ & $\begin{array}{c}\text { Start-up } \\
\text { Clubs }\end{array}$ & $\begin{array}{c}\text { Technology } \\
\text { Transfers }\end{array}$ & Patents & Publications \\
\hline $\begin{array}{c}\text { Start-ups } \\
\text { Start-up Classes }\end{array}$ & 0.846 & 0.333 & 1.000 & & & \\
Start-up Clubs & 0.311 & 0.303 & 0.950 & & & \\
Technology & 0.444 & 0.208 & 0.515 & 0.942 & & \\
Transfers & 0.566 & 0.193 & 0.328 & 0.875 & 0.954 & \\
$\quad \begin{array}{c}\text { Patents } \\
\text { Publications }\end{array}$ & 0.349 & 0.252 & 0.532 & 0.828 & 0.711 & 1.000 \\
\hline
\end{tabular}

Note 1: Leading diagonal shows the squared root of AVE of each construct. *Criteria: The square root of AVE for each construct (diagonal term) exceeded the correlations between the construct and other constructs (off-diagonal terms) by Fornell and Larcker [65].

All paths' significances were specifically analyzed and tested using a bootstrap resampling procedure. Start-up clubs significantly influence both patents, with a path coefficient $(\beta)=0.297$, and publications, with $\beta=0.502$ at $p<0.01$. These results statistically mean that the ideas derived from start-up clubs in 2014 could affect patent applications and registration or publications in 2015.

Start-up classes positively and significantly influenced only publications, at $p<0.05$. Start-up clubs offered five times more influence on publication than start-up classes. These results shows that ideas derived from the start-up class in 2014 might statistically affect the publication in 2015, but did not lead to patents.

Patents significantly influenced both technology transfer, with $\beta=0.581$, and start-ups, with $\beta=0.643$ at $p<0.01$. This means that the ideas or technologies, verified for the commercialization possibility through disclosed patents in 2015, could be statistically linked to (1) technology transfer numbers to companies and sales and (2) start-up numbers and sales in 2016.

Publication only has a significant influence on technology transfer $(\beta=0.416, p<0.01)$. These results mean that while ideas, embodied in publications in 2015, are difficult to have a statistical impact on start-ups, they could be major sources of technology transfer.

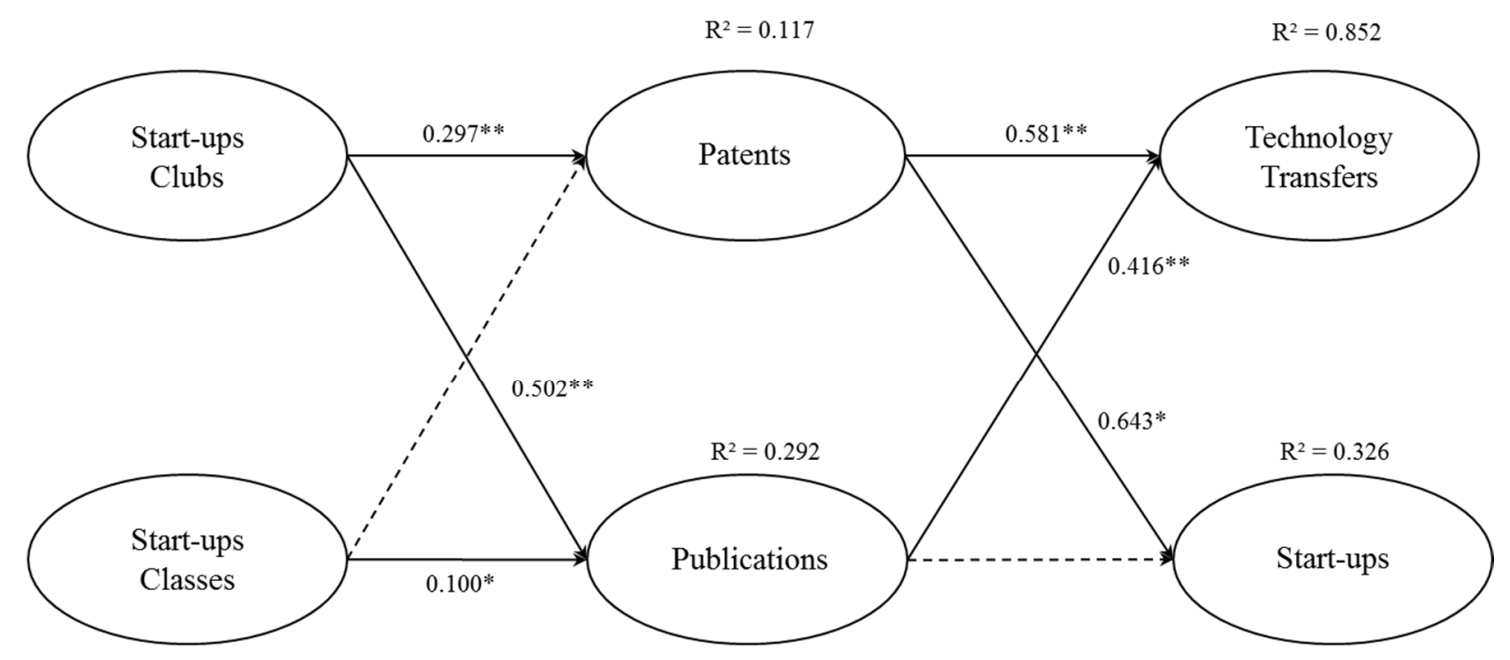

Notes: ${ }^{*} p<0.05,{ }^{* *} p<0.01$, dotted line: nonsignificant at the 0.05 level.

Figure 2. The path analysis results. 
The explanatory powers (R2) for technology transfer (0.852), start-ups (0.326), patents (0.117) and publications (0.292) far surpassed the accepted threshold of 0.1 [69]. These values represent goodness of fit of each causal relationship model as a capability to describe and predict the real phenomenon, and the closer it is to 1 , the better the explanation.

\section{Discussion and Implications}

\subsection{Discussion of Findings}

This study aimed to identify the causal relationship for an UTC mechanism based on a dynamic capabilities framework. We discussed some important points based on the model's results.

Our findings revealed that opportunities' identification correlated with the sensing ability, in exploring ideas in start-up clubs and classes. Our path analysis concretely indicates that start-up clubs' activities played more important roles in linking with ideas, such as patents and publications, than formal start-up classes. It means that it is important to voluntarily participate and freely generate discussions to explore novel, innovative ideas. On the other hand, it is relatively difficult to discover novel ideas in formal classes when considering the cultural features of universities in Korea and natural characteristics of Korean students. Korean students often passively participate in class, even when asked to communicate their ideas [70,71]. This finding is in the same vein as the existing study. Hallam and Novick [72] asserted that when the institutional culture is relatively strict and has a hierarchical nature, it represents a significant obstacle to achieving commercialization of technology. Second, we suggested two intellectual property (IP) types regarding idea specification, such as patents and research publications. As shown in previous studies, IP such as patents and research publications held by universities is major consideration in technology transfer activities and industry-university collaborative ventures for a long time $[73,74]$. We empirically identified a significant relationship among these IP and commercialization activities; however, research publications do not positively relate to start-ups. As research publications are the category of IP that focuses on theory, with rough and general practical implications, it can be difficult to use to key resources for start-ups, because of a relative lack of idea specifications. However, ideas in research publications could be used as key technology transfer resources by co-developing or collaborating with research firms and other organizations [75].

\subsection{Implications}

This study provided several important theoretical implications. We applied the dynamic capabilities framework, generally used for business-oriented environments, to link the antecedents and outcomes of university technology commercialization in research-oriented organizations. This study recognized the idea as a resource and capability for UTC, and suggested new activities related to the development process of ideas using each dynamic capability. This application in a new and fresh context theoretically extended the availability of dynamic capabilities. Further, the dynamic capabilities frameworks that have been primarily applied to qualitative research, such as case studies or interviews, were applied to quantitative data, including numeric panel data. This attempt also indicates the new application of dynamic capabilities.

We provided a causal relationship model, from sensing to transforming capabilities, to commercialize ideas through a longitudinal study with panel datasets over three years. Specifically, we simultaneously considered revenue as quality and the number as quantity in idea commercialization. The model suggests a conceptual model to operate sustainable UTC with balanced measurement items, and will provide useful conceptual foundation for future UTC research.

We addressed such new idea exploration activities as start-up clubs and classes. Intellectual human capital is critical, given the university's importance in successful technology commercialization. Looking upon start-up clubs and classes as the first step of the sustainable idea commercialization mechanism, these programs must be continuously researched based on our theoretical findings. 
Our empirical logic has several practical implications. Our findings identify the importance of start-up clubs as a first step for idea exploration in university technology commercialization. When considering the increased importance of start-up clubs over start-up classes in sensing capabilities, the university should provide academic and practical support, simultaneously ensuring these clubs' autonomy. For example, the university could develop start-up clubs with various interdisciplinary approaches, a systematic support system, practitioner networking and a challenging venture culture. Further, it is necessary to provide innovative content to trigger a two-way interaction with students in start-up classes.

In the process from specifying ideas to commercializing them, we identified patents as important for both technology transfers and start-ups. Despite this importance, many Korean universities that only focus on short-term performance still lack for attention and capabilities for patent development. Since patent applications requires complex procedures, and substantial costs and time. However, it is necessary to provide support and policies in the long-term to encourage patent development, considering that it is an important capability to improve the university competitiveness through sustainable technology commercialization.

As publication is also an important resource in technology licensing, the university and researchers carefully focus on the application of and actualization plan for research publications. Swamidass [76] implies that start-ups are more highly economically valued than technology licenses in the United States. Moreover, Korean universities also have a significant interest in start-ups, under the government policies for activating them. However, the descriptive results in Table 2 demonstrated that technology transfer was a primary revenue source of UTC, compared to start-ups. In addition to the interest in the start-ups environment, the proactive role of TTOs in universities was important to sell or license the technology.

\subsection{Limitation and Future Research}

This study's findings were subject to several limitations, and these could convey potential topics for future research. First, regarding start-up classes and publications, it is important to measure both their quantity and quality to elaborate on the role of their antecedents. However, because of the panel data's limitation, we could not determine the quality of dynamic capabilities, such as start-up classes and publications. Thus, future research must obtain additional datasets to measure the variables' various dimensions.

Second, this study did not address a detailed strategy for technology diffusion mechanisms. This is quite relevant to the survival rate of startups in the market. However, since the panel datasets used in this study are mainly indicators to measure the current state of Korean university environment, it is difficult to analyze the survival rate after start-ups. Thus, we should consider how to sell research output to technology markets, or how to manage start-ups to diffuse their products or services based on a transformed idea for useful and practical implications. We anticipate future research should include marketing and management strategies to address the technology diffusion issue. One of the conceptual frameworks to deal with technology diffusion is to use sectorial and technological systems of innovation covering technological regimes, market demand, public policy in a certain sector [48].

Finally, this study only collected sample data from universities in Korea. Methods of idea exploration and exploitation may differ in universities across cultures and nations, and it is difficult to generalize the findings to every university. It would be worthwhile to consider replicating our framework for other nations. Moreover, a useful study would compare other nations' factors that may be more effective for commercialization.

\section{Conclusions}

Despite the high interest and investment in start-ups and technology transfers in Korean universities, the performance from UTC does not appear as much as the US or the European nations [77]. This study tried to analyze the reason for the performance gap among them with dynamic capability theory. 
First, regarding RQ1, this study identified the importance of start-ups clubs in universities to explore the initial idea for UTC. As mentioned in the first practical implication for creative ideas, free and informal student-led start-up activities should be active in a university.

In this process, universities should provide entrepreneurship mentoring program, marketing of products and services developed by the club, media releases and legal support as well as financial and material supports to encourage start-up clubs [78].

Regarding the start-up class, it is difficult for students who went through a one-way and spoon-feeding style education through elementary school to high school to propose creative ideas through active communication in the classes. Therefore, new student-led education methods such as a problem based learning (PBL), team based learning (TBL), discussion based learning (DBL) and capstone design project to encourage students involvement are needed for start-up classes. Our results could provide political implications on education and start-up environment to countries such as China or Japan that have similar education methods, culture and environment.

Regarding RQ2, this study provided an idea-oriented UTC mechanism based on dynamic capabilities framework with three years longitudinal dataset of universities in South Korea. This study was the first attempt to apply dynamic capabilities, used in the business sector, to the education and research sector. Simultaneously considering two types of UTC such as technology transfers and start-ups, this study gave a useful framework into how an idea is sensed, seized and transformed by university members. Furthermore, given that the UTC is considered as relevant market opportunities and a key factor within the national innovation processes [48], our findings offered new directions for university policy makers to activate the UTC.

Finally, regarding RQ3, it has been statistically verified that the patents and publications are significant meaningful activities for technology transfer or start-up in UTC process [79]. When analyzing the research related with knowledge transfer and university-business relationship during 2013 to 2016, the most discussed topic was the economic impact of university-business relation. However, when analyzing the patents and the publications conducted by universities in Korea, they show a lack of concern about university-business relation for commercialization. This is because research quantity is considered more important than the research content when a university is evaluated by Korean Ministry of Education. Therefore, developing a new evaluation method is important in order to encourage research concerning commercialization.

Author Contributions: Conceptualization, I.C. and Y.H.K.; methodology, J.J.; formal analysis, J.J.; investigation, I.C.; writing — original draft preparation, I.C.; writing—review and editing, J.J.; supervision, Y.H.K.

Funding: This research received no external funding.

Conflicts of Interest: The authors declare no conflict of interest.

\section{References}

1. Carayannis, E.G.; Dubina, I.N.; Ilinova, A.A. Licensing in the Context of Entrepreneurial University Activity: An Empirical Evidence and a Theoretical Model. J. Knowl. Econ. 2015, 6, 1-12. [CrossRef]

2. Azoulay, P.; Ding, W.; Stuart, T. The determinants of faculty patenting behavior: Demographics or opportunities? J. Econ. Behav. Organ. 2007, 63, 599-623. [CrossRef]

3. Qian, X.-D.; Xia, J.; Liu, W.; Tsai, S.-B. An empirical study on sustainable innovation academic entrepreneurship process model. Sustainability 2018, 10, 1974.

4. Powers, J.B.; McDougall, P.P. University start-up formation and technology licensing with firms that go public: A resource-based view of academic entrepreneurship. J. Bus. Ventur. 2005, 20, 291-311. [CrossRef]

5. Miner, A.S.; Gong, Y.; Ciuchta, M.P.; Sadler, A.; Surdyk, J. Promoting university startups: International patterns, vicarious learning and policy implications. J. Technol. Transf. 2012, 37, 213-233. [CrossRef]

6. Åstebro, T.; Bazzazian, N.; Braguinsky, S. Startups by recent university graduates and their faculty: Implications for university entrepreneurship policy. Res. Policy 2012, 41, 663-677. [CrossRef] 
7. Avnimelech, G.; Feldman, M.P. The stickiness of university spin-offs: A study of formal and informal spin-offs and their location from 124 US academic institutions. Int. J. Technol. Manag. 2015, 68, 122-149. [CrossRef]

8. Bray, M.J.; Lee, J.N. University revenues from technology transfer: Licensing fees vs. equity positions. J. Bus. Ventur. 2000, 15, 385-392. [CrossRef]

9. Hameed, T.; Von Staden, P.; Kwon, K.-S. Sustainable economic growth and the adaptability of a national system of innovation: A socio-cognitive explanation for South Korea's mired technology transfer and commercialization process. Sustainability 2018, 10, 1397. [CrossRef]

10. Siegel, D.S.; Veugelers, R.; Wright, M. Technology transfer offices and commercialization of university intellectual property: Performance and policy implications. Oxf. Rev. Econ. Policy 2007, 23, 640-660. [CrossRef]

11. Teece, D.J. Explicating dynamic capabilities: The nature and microfoundations of (sustainable) enterprise performance. Strateg. Manag. J. 2007, 28, 1319-1350. [CrossRef]

12. Wilden, R.; Gudergan, S.P.; Nielsen, B.B.; Lings, I. Dynamic capabilities and performance: Strategy, structure and environment. Long Range Plan. 2013, 46, 72-96. [CrossRef]

13. Helfat, C.E.; Peteraf, M.A. The dynamic resource-based view: Capability lifecycles. Strateg. Manag. J. 2003, 24, 997-1010. [CrossRef]

14. Teece, D.J.; Pisano, G.; Shuen, A. Dynamic capabilities and strategic management. Strateg. Manag. J. 1997, 18, 509-533. [CrossRef]

15. Winter, S.G. Understanding dynamic capabilities. Strateg. Manag. J. 2003, 24, 991-995. [CrossRef]

16. Wernerfelt, B. A resource-based view of the firm. Strateg. Manag. J. 1984, 5, 171-180. [CrossRef]

17. Li, D.-Y.; Liu, J. Dynamic capabilities, environmental dynamism, and competitive advantage: Evidence from China. J. Bus. Res. 2014, 67, 2793-2799. [CrossRef]

18. Helfat, C.E.; Peteraf, M.A. Managerial cognitive capabilities and the microfoundations of dynamic capabilities. Strateg. Manag. J. 2015, 36, 831-850. [CrossRef]

19. Ambrosini, V.; Bowman, C. What are dynamic capabilities and are they a useful construct in strategic management? Int. J. Manag. Rev. 2009, 11, 29-49. [CrossRef]

20. Drnevich, P.L.; Kriauciunas, A.P. Clarifying the conditions and limits of the contributions of ordinary and dynamic capabilities to relative firm performance. Strateg. Manag. J. 2011, 32, 254-279. [CrossRef]

21. Tsai, S.P. Dynamic marketing capabilities and radical innovation commercialisation. Int. J. Technol. Manag. 2015, 67, 174-195. [CrossRef]

22. Bruni, D.S.; Verona, G. Dynamic marketing capabilities in Science-based firms: An exploratory investigation of the pharmaceutical industry. Br. J. Manag. 2009, 20, S101-S117. [CrossRef]

23. Pandza, K.; Thorpe, R. Creative search and strategic sense-making: Missing dimensions in the concept of dynamic capabilities. Br. J. Manag. 2009, 20, S118-S131. [CrossRef]

24. O'Connor, G.C.; Paulson, A.S.; DeMartino, R. Organisational approaches to building a radical innovation dynamic capability. Int. J. Technol. Manag. 2008, 44, 179-204. [CrossRef]

25. Birkinshaw, J.; Zimmermann, A.; Raisch, S. How Do Firms Adapt to Discontinuous Change? Bridging the Dynamic Capabilities and Ambidexterity Perspectives. Calif. Manag. Rev. 2016, 58, 36-58.

26. Weerawardena, J.; O'Cass, A. Exploring the characteristics of the market-driven firms and antecedents to sustained competitive advantage. Ind. Mark. Manag. 2004, 33, 419-428. [CrossRef]

27. Aldieri, L.; Kotsemir, M.; Vinci, C.P. The role of environmental innovation through the technological proximity in the implementation of the sustainable development. Bus. Strategy Environ. 2019. [CrossRef]

28. Siegel, D.S.; Waldman, D.A.; Atwater, L.E.; Link, A.N. Commercial knowledge transfers from universities to firms: Improving the effectiveness of university-industry collaboration. J. High. Technol. Manag. Res. 2003, 14, 111-133. [CrossRef]

29. Ko, C.-R.; An, J.-I. Success Factors of Student Startups in Korea: From Employment Measures to Market Success. Asian J. Innov. Policy 2019, 8, 97-121.

30. Rampersad, G.C. Developing university-business cooperation through work-integrated learning. Int. J. Technol. Manag. 2015, 68, 203-227. [CrossRef]

31. Kuratko, D.F.; Hodgetts, R.M. Entrepreneurship: Theory Process, Practice; South Western Publishing Co.: Mason, $\mathrm{OH}, \mathrm{USA}, 2004$. 
32. Stagars, M. University Startups and Spin-Offs: Guide for Entrepreneurs in Academia; Apress: New York, NY, USA, 2014.

33. Charney, A.; Libecap, G.D. The impact of entrepreneurship education: An evaluation of the Berger Entrepreneurship Program at the University of Arizona, 1985-1999. SSRN 2000. [CrossRef]

34. Ortbach, K.; Plattfaut, R.; Poppelbuß, J.; Niehaves, B. A dynamic capability-based framework for business process management: Theorizing and empirical application. In Proceedings of the 2012 45th Hawaii International Conference on System Science (HICSS), Washington, DC, USA, 4-7 January 2012.

35. Basadur, M.; Pringle, P.; Speranzini, G.; Bacot, M. Collaborative problem solving through creativity in problem definition: Expanding the pie. Creat. Innov. Manag. 2000, 9, 54-76. [CrossRef]

36. Zemlickiene, V.; Mačiulis, A.; Tvaronavičienè, M. Factors impacting the commercial potential of technologies: Expert approach. Technol. Econ. Dev. Econ. 2017, 23, 410-427. [CrossRef]

37. Fischer, T.; Gebauer, H.; Gregory, M.; Ren, G.; Fleisch, E. Exploitation or exploration in service business development? Insights from a dynamic capabilities perspective. J. Serv. Manag. 2010, 21, 591-624. [CrossRef]

38. Lichtenstein, B.M.B.; Brush, C.G. How do" resource bundles" develop and change in new ventures? A dynamic model and longitudinal exploration. Entrep. Theory Pract. 2001, 25, 37-58. [CrossRef]

39. Gans, J.S.; Stern, S. The product market and the market for "ideas": Commercialization strategies for technology entrepreneurs. Res. Policy 2003, 32, 333-350. [CrossRef]

40. Sharfman, M.P.; Dean, J.W., Jr. Flexibility in strategic decision making: Informational and ideological perspectives. J. Manag. Stud. 1997, 34, 191-217. [CrossRef]

41. Diehl, M.; Stroebe, W. Productivity loss in brainstorming groups: Toward the solution of a riddle. J. Personal. Soc. Psychol. 1987, 53, 497. [CrossRef]

42. Di Gregorio, D.; Shane, S. Why do some universities generate more start-ups than others? Res. Policy 2003, 32, 209-227. [CrossRef]

43. Elfenbein, D.W. Publications, patents, and the market for university inventions. J. Econ. Behav. Organ. 2007, 63, 688-715. [CrossRef]

44. Gebauer, H. Exploring the contribution of management innovation to the evolution of dynamic capabilities. Ind. Mark. Manag. 2011, 40, 1238-1250. [CrossRef]

45. Aerts, K.; Matthyssens, P.; Vandenbempt, K. Critical role and screening practices of European business incubators. Technovation 2007, 27, 254-267. [CrossRef]

46. Rothaermel, F.T.; Agung, S.D.; Jiang, L. University entrepreneurship: A taxonomy of the literature. Ind. Corp. Chang. 2007, 16, 691-791. [CrossRef]

47. Weckowska, D.M. Learning in university technology transfer offices: Transactions-focused and relations-focused approaches to commercialization of academic research. Technovation 2015, 41, 62-74. [CrossRef]

48. Makkonen, T.; Inkinen, T. Sectoral and technological systems of environmental innovation: The case of marine scrubber systems. J. Clean. Prod. 2018, 200, 110-121. [CrossRef]

49. Markman, G.D.; Siegel, D.S.; Wright, M. Research and technology commercialization. J. Manag. Stud. 2008, 45, 1401-1423. [CrossRef]

50. González-Pernía, J.L.; Kuechle, G.; Peña-Legazkue, I. An assessment of the determinants of university technology transfer. Econ. Dev. Q. 2013, 27, 6-17. [CrossRef]

51. Markman, G.D.; Phan, P.H.; Balkin, D.B.; Gianiodis, P.T. Entrepreneurship and university-based technology transfer. J. Bus. Ventur. 2005, 20, 241-263. [CrossRef]

52. Franklin, S.J.; Wright, M.; Lockett, A. Academic and surrogate entrepreneurs in university spin-out companies. J. Technol. Transf. 2001, 26, 127-141. [CrossRef]

53. Wright, M.; Lockett, A.; Clarysse, B.; Binks, M. University spin-out companies and venture capital. Res. Policy 2006, 35, 481-501. [CrossRef]

54. Bozeman, B. Technology transfer and public policy: A review of research and theory. Res. Policy 2000, 29, 627-655. [CrossRef]

55. Shane, S. Technological opportunities and new firm creation. Manag. Sci. 2001, 47, 205-220. [CrossRef]

56. Higher Education in KOREA. Available online: https://www.academyinfo.go.kr/index.do?lang=en (accessed on 28 October 2017). 
57. Desimone, L.M.; Porter, A.C.; Garet, M.S.; Yoon, K.S.; Birman, B.F. Effects of professional development on teachers' instruction: Results from a three-year longitudinal study. Educ. Eval. Policy Anal. 2002, 24, 81-112. [CrossRef]

58. Zahra, S.A.; Nielsen, A.P. Sources of capabilities, integration and technology commercialization. Strateg. Manag. J. 2002, 23, 377-398. [CrossRef]

59. Tseng, A.A.; Raudensky, M. Performance evaluations of technology transfer offices of major US research universities. J. Technol. Manag. Innov. 2014, 9, 93-102. [CrossRef]

60. Abdi, H. Partial least square regression (PLS regression). Encycl. Res. Methods Soc. Sci. 2003, 6, $792-795$.

61. Chin, W.W.; Marcolin, B.L.; Newsted, P.R. A partial least squares latent variable modeling approach for measuring interaction effects: Results from a Monte Carlo simulation study and an electronic-mail emotion/adoption study. Inf. Syst. Res. 2003, 14, 189-217. [CrossRef]

62. Geladi, P.; Kowalski, B.R. Partial least-squares regression: A tutorial. Anal. Chim. Acta 1986, 185, 1-17. [CrossRef]

63. Westad, F.; Marten, H. Variable selection in near infrared spectroscopy based on significance testing in partial least squares regression. J. Near Infrared Spectrosc. 2000, 8, 117-124. [CrossRef]

64. Wold, S.; Ruhe, A.; Wold, H.; Dunn, W.J., III. The collinearity problem in linear regression. The partial least squares (PLS) approach to generalized inverses. Siam J. Sci. Stat. Comput. 1984, 5, 735-743.

65. Fornell, C.; Larcker, D.F. Evaluating structural equation models with unobservable variables and measurement error. J. Mark. Res. 1981, 18, 39-50. [CrossRef]

66. Gefen, D.; Straub, D.; Boudreau, M.-C. Structural equation modeling and regression: Guidelines for research practice. Commun. Assoc. Inf. Syst. 2000, 4, 7. [CrossRef]

67. Henseler, J.; Sarstedt, M. Goodness-of-fit indices for partial least squares path modeling. Comput. Stat. 2013, 28, 565-580. [CrossRef]

68. Tenenhaus, M.; Vinzi, V.E.; Chatelin, Y.-M.; Lauro, C. PLS path modeling. Comput. Stat. Data Anal. 2005, 48, 159-205. [CrossRef]

69. Falk, R.F.; Miller, N.B. A Primer for Soft Modeling; University of Akron Press: Akron, OH, USA, 1992.

70. Cho, B.-E. Issues concerning Korean learners of English: English education in Korea and some common difficulties of Korean students. East. Asian Learn. 2004, 1, 31-36.

71. Jang, D.-H.; Kim, L. Framing “world class" differently: International and Korean participants' perceptions of the world class university project. High. Educ. 2013, 65, 725-744. [CrossRef]

72. Hallam, C.; Novick, D.; Gilbert, D.J.; Frankwick, G.L.; Wenker, O.; Zanella, G. Academic entrepreneurship and the entrepreneurial ecosystem: The UT transform project. Acad. Entrep. J. 2017, 23, 77-90.

73. Santoro, M.D.; Gopalakrishnan, S. Relationship dynamics between university research centers and industrial firms: Their impact on technology transfer activities. J. Technol. Transf. 2001, 26, 163-171. [CrossRef]

74. Reams, B.D. University-Industry Research Partnerships; Quorum: Cheltenham, UK, 1986.

75. Ju, H.; Zhang, S.; Zhao, S.; Ju, X. Knowledge transfer capacity of universities and knowledge transfer success: Evidence from university-industry collaborations in China. Int. J. Technol. Manag. 2016, 71, 278-300. [CrossRef]

76. Swamidass, P.M. University startups as a commercialization alternative: Lessons from three contrasting case studies. J. Technol. Transf. 2013, 38, 788-808. [CrossRef]

77. Vinig, T.; Lips, D. Measuring the performance of university technology transfer using meta data approach: The case of Dutch universities. J. Technol. Transf. 2015, 40, 1034-1049. [CrossRef]

78. Lee, S.-J.; Lee, Y.-M. What policy approaches are needed to improve startup education in university. Int. Inf. Inst. (Tokyo) Inf. 2015, 18, 3833.

79. Ripoll Feliu, V.; Diaz Rodriguez, A. Knowledge transfer and university-business relations: Current trends in research. Intang. Cap. 2017, 13, 697-719. [CrossRef]

(C) 2019 by the authors. Licensee MDPI, Basel, Switzerland. This article is an open access article distributed under the terms and conditions of the Creative Commons Attribution (CC BY) license (http://creativecommons.org/licenses/by/4.0/). 